\title{
Studying the Effects of Human Resource Information System on Corporate Performance
}

Laith T. Khrais, Department of Business Administration, College of Applied Studies and Community Service, Imam Abdulrahman Bin Faisal University, Dammam, Saudi Arabia, ORCID 0000-0002-0261-6146

Osman S. Shidwan, Department of Business Administration, College of Applied Studies and Community Service, Imam Abdulrahman Bin Faisal University, Dammam, Saudi Arabia, ORCID 0000-0002-0777-7950

Ahmed Alafandi, Department of Business Administration, College of Applied Studies and Community Service, Imam Abdulrahman Bin Faisal University, Dammam, Saudi Arabia, ORCID 0000-0002-4983-5485

Norah Yousif Alsaeed, Department of Business Administration, College of Applied Studies and Community Service, Imam Abdulrahman Bin Faisal University, Dammam, Saudi Arabia, ORCID 0000-0003-0374-397X

\begin{abstract}
This paper is quantitative research based on the impacts of the Human Resource Information System (HRIS) on manufacturing firms in the Middle East. The HRIS plays a significant role that assists in the effectiveness of Human Resource Management (HRM). In this case, the study aims at inspecting the impacts of HRIS on the effectiveness of HRM in the selected manufacturing firms in the Middle East. The HRIS is a measure of a five-dimensional structure of the effective communication, top management, human resource management, and training information system that is incorporated with the measure of the effectiveness of the HRM in the recruitment, performance, and planning of the functions of human resource in the selected firms. The data is obtained from a secondary survey and analysed using SPSS. The results revealed that the HRIS explains approximately $85 \%$ of the selected manufacturing firms in the Middle East variance in the HRM. Therefore, the manufacturing companies need to adopt the HRIS system since it has positive impacts on the effectiveness of the HRM in the management of these manufacturing companies.
\end{abstract}

Keywords: Human Resource, Information System, HRIS, Effectiveness of Human Resource Management, Manufacturing Firms, Performance, Corporate

Received: 07.12.2020 $\quad$ Accepted: 20.01.2021 $\quad$ Published: 04.02.2021

\section{INTRODUCTION}

The HRIS is a desired system used in manipulating, acquiring, storing, and distributing the required information based on the human resource system of an organization (Trivena and Silintowe, 2019). It is a database aimed at the procedural systems of recruitment, job qualification, hiring procedure, and professional development in the workforce of employee diversity. An effective department of human resources allows the employees to contribute to the production of the organization as it accomplishes its goals and objectives effectively. The HRIS system incorporates the use of new information technology in managing the human resource of an organization that involves the electronic system and the process of HRM (Torres-Coronas and Arias-Oliva, 2018).

The application of this HRIS system has been a key factor of consideration in the HRM of manufacturing firms. Previously, the manufacturing sector has been using this HRIS system to manage the talents of humans. Recently, these organizations began automated electronic systems in the act of introducing the specialised HRIS that aims at reducing the transaction routine based on the activities of traditional resource that deals with the advanced transformational ideas (Sulastri, 2018). The use of the HRIS involves the interaction process of the information technology and the human resource management system that integrates a database that shared by the human resource as they provide a common language that integrates and service and effectiveness of the HRIS.

\section{Statement of the Problem}

Previous studies (Sulastri, 2018; Soule, 2018) provided a piece of clear evidence that the use of this HRIS system affects the effectiveness of HRM systems in the manufacturing companies. Rao (2017) discussed the possible contribution of this HRIS system based on competence in job analysis as it approaches the performance of an organization. In the application of the HRIS system, it is based on the decision of employees that benefits the organization more as it increases the innovation and motivation on the willingness of employees to be involved in the plans of the organization (Soule, 2018). The application of 
the HRIS system results in an increased commitment in the process of service provision to increase productivity and profitability based on the contribution of the effective organizational sector. The finding of this research will try to enlighten the literature on the HRIS system and the effectiveness of HRM. The findings will be based on the literature gap as it tries to investigate how the HRIS has impacted on HRM in the selected apparel manufacturing firms in the Middle East that give the impacts of the HRIS to the effectiveness of HRM (Rainer and Cegielski, 2020).

Therefore, the main research questions of the study are:

$>$ What are the effects of the Human Resource Information System on the manufacturing companies in the Middle East?

$>$ What is the relationship between the process and activities of human resource management in manufacturing companies to the use of electronic systems?

$>$ Does the use of the Human Resource Information System in the manufacturing companies have any impact on production and marketing?

\section{Significance of the Research}

The study aims at determining the impacts of the use of the HRIS system in the HRM of the manufacturing companies in the Middle East. In this case, the study is crucial in the fact of improvement of the systems of HR in these companies that incorporate the use of information technology. The application of this HRIS system aims at improving the production of the manufacturing companies hence making them incorporate on the other sectors that may need the demand for the required technological improvement in the production sector. Improving the production leads to increased profits in these companies that encompass the increased production in the manufacturing companies in the Middle East. In this case, other engineering sectors would also determine the impact of the HRIS system application in the HRM and apply the same to increase their production hence profitability. The research is so significant to not only manufacturing companies but also other production companies across the globe. The HRIS is a tool effectively used in correctly aligning the roles of the department of human resources in a manufacturing organization.

\section{LITERATURE REVIEW}

The concept of this HRM system was first defined as general modes of activities in any operational management of the organization by utilising the available resources, especially labour, to attain the firm's set objectives (Pouransari, 2016). The function is related to maintenance through stratified planning, controlling, recruitment and hiring, motivation, and remuneration. These functions, when integrated with proper management information systems, they spur the practices and performance of the firm higher. All these practices of understanding, maintenance, development, and suitable employment policies are accomplished via the matching model. Payne and Petrenko (2019) argued that the matching model of the HRM holds that HR systems and firms approach and further described that there is a known human resource cycle in companies. The comprises four stages; training programs, information technology, communication system, and human resource system. The stages are executed in all entities and especially banks listed on stock exchanges. Banks have to execute the following processes to fit in the system of Stock Exchanges whose prices fluctuate from time to time.

The stock exchange market includes selection, evaluation, compensation, and development. Therefore, the managers ought to devise ways to ensure how their employees have involved in the stages profits the bank and especially a competitive edge in attracting investors. HRM should not remain independent of other departments in the bank and especially the finance and credit control sector. The practices executed should have virtue aspects to fit in the Capital Market Authority (Osei Nyame and Boateng, 2016). The manufacturing companies are part of the global competitive markets in the engineering sector, and they force the business to manage all human factors at entry-level. The system also appraises the process of employees as opposed by the traditional approach in HRM that allows information sharing during the processes of appraisal in the manufacturing companies (Rainer and Cegielski, 2020).

\section{Differences between HRIS and HRM}

There is a rapid demand for management information systems in operational areas in banks (Khrais, 2018; 2020). The need has been indicated by finance, marketing, accounting, and procurement (Laith. The definition is somewhat analogous to the previous definition of IS (Longenecker, 2019). However, the HRIS definition accentuates data about the employees of an organization, which is diverse from conservative structural systems, which centres on extinct data, that managers utilise for forecasting and decision- 
making. Thus, it is very indispensable to ascertain, which employees and job applicants communicate and interact with companies, to enhance connections, and obtain main HRM services.

Additionally, the HRIS has a unique feature, in that it enables companies in encouraging, appealing, and retaining workforces, which are vital factors in eradicating competition from other organizations, in attracting as well as retain gifted and experienced workers (Kavanagh, Thite and Johnson, 2017; Kolatshi, 2017). Besides, Keenan (2020) stated that the HRIS backs the interaction, communication, and service aim based on HR procedures such as, e-learning, e-recruiting, and e-benefits. These are different from central HR systems, which only include professionals' basic profiles and application of HR for "customer-facing" systems. The system eases various functions like appraising employee performance, selecting and hiring qualified workers, managing worker welfares, training workers, as well as a range of other activities in the system of human management (Longenecker, 2019).

\section{THEORETICAL REVIEW}

\section{Resource-Based View Theory}

The information technology can aid advance organization performance is a vital study matter in the systems of information research (Khrais, 2019; 2020). The resource-based view (RBV) system was postulated in 1984 by Wernerfelt as a major philosophy that has been embraced to investigate the matter (Hogler, 2016). The fundamental debate of RBV is based on the performance of the firm that is determined by the HRM. When the RBV is practical to scrutinise the result of information technology (IT), the IT is measured as a resource of an organization that can advance firm competencies and ultimately leads to high performance. The RBV system is useful in analysing the worth of IT, information systems that are usually deliberated to be a known type of resource. Some argue that administrative resources that create a benefit that has the following characteristics: valuable where the human resource enables the firm to implement or apprehend the plans that advance its efficacy in manufacturing companies, rare where the human resources are not controlled by a huge number of conflicting firms, incorrectly imitable where the human resources are not effortlessly copied due to matchless past conditions, causally unclear, non-sustainable, and social complex where the resource is not be easily replaced in the companies by other substitutes. Cost reduction includes Cost of Goods Sold (COG/S) and Selling, General, and Administrative expenses (SGA/S), which examines the influence of IS on the functioning proficiency of a firm. Other superior pointers are being used in certain situations, such as customer satisfaction. The research included industrial factors as controlling variables towards the choice of IS resources in the manufacturing companies.

\section{Resource-Based view in the context of Information Systems}

The human resource-based studies and analysis of the potentials of IT as an important resource that creates a continued competitive edge was conducted. Hanif (2017), in his research, developed a resourcebased model and recognised some characteristics of IT as human resource and also mentioned on whether they are a source which is sustained to competitive advantage. The factors are identified on the early works lined maintainable advantage could be reached based on the placement of IT by the locking customers (Georgiades, 2015). The flexibility of technical IT skills indicates that such prowess is clear and easily adjustable and hence cannot generate a competitive advantage. IT administrative skills, which are a skill that is very inferred by nature, developed over the years of comprehending or appreciating the capabilities of IT and the needs of the business can become a source of unrelenting competitive advantage according to the examiners. Some scholars linked IT capability with firm productivity. IT's an ability, according to them, is the ability to activate and position IT-based resources in combination or co-present with other resources. The application of the HRIS system in human resource management of the manufacturing companies (Daniel, 2017).

The IT resources were classified into three categories: Firstly, IT infrastructure: This is merely the physical IT infrastructure that creates the basis of the firm's IT assets (Eckert, 2016). Some works criticise that IT cannot be a source of continuous competitive advantage where the view is termed as nothing but reductionist that pursues to measure the infrastructure solely in terms of individual compositions, disregarding the synergistic perspective of advantages from cohesive systems. The author related integrated versus non-integrated IT and indicated that the non-integrated category limits an organization 's preference and has little effect on a firm's general productivity (Daniel, 2017). Secondly, human IT resources consist of managerial and technical expertise. There is an agreement on the view that administrative skills are inferred in its nature and cannot be ordered. Some of the basic roles of the Human IT resources are integrating IT with business planning procedures more sustainably, formulate dependable and cost-effective presentations that back business requirements of the firm faster than 
rivalry. Thus, we deem that it is from the Human IT resources that IT can start to become incorrectly imitable by creating the link between human resources and productivity (Eckert, 2016). Thirdly, IT enables Intangibles, and scholars mentioned that utilisation of IT could result in advanced customer care service, improved product quality, amplified market receptiveness, and better collaboration between buyers and suppliers. They integrate research outcomes and classify the Intangibles in three classes: customer orientation, which includes IT-enabled association management through (CRM), expansion of knowledge assets, and collaboration; the ability to collaborate among departments (Eckert, 2016).

\section{Empirical Review}

The HRM system matters based on the key apprehension for the managers on all levels since they attain their objectives through the labours of others, which need the operative and competent management of employees. The spacious grouping of the activities of HRM, for instance; selection, recruiting, and training, are just a few places of the massive errands on supervisors and administrators as well in the firms. These embraces are examining jobs, strategizing labour needs the process of recruiting and training new employees, managing benefits, communication that entails disciplining and counselling, and upholding the commitment of these employees. Essentially, HRIS is engaged towards the department of HR in the firms. Still, the utilisation of the HRIS can necessitate some advantages not only to the functions of the HR department but also to the line managers and the larger institution. The application of the HRIS has encouraged as a chance for HR specialists to become tactical partners with the executive team (Buzkan, 2016). HRIS permits the HR role to be more resourceful and to deliver better information in facilitating the decision-making process. The roles of this HRIS have some distinct connection with the functions of the HRM in the firms.

Buzkan (2016) argued that the system was specifically found that tactical integration, human resources scrutiny, predicting and planning, and incorporative communication have no relationship with the HR practices. Also, Adekola and Sergi (2018) found that the performance expansion, knowledge administration, and compliance on records as scopes of the HRIS in the firms that have a relationship with the HR practices, especially for listed entities. HRIS gives administration with several strategic advantages HRIS. Similarly, Bohlander and Snell (2019) highlighted five motives on why companies should utilise HRIS. Firstly, the HRIS could scale high competitiveness by advancing HR operations to concur with the stock exchange. Secondly, the HRIS produces a greater diversity and number of the HR-related reports, especially on how banks can work in hand with the stock exchange. Thirdly, divert the determination of the HR on the processing of strategic transactions of the HRM in the firms. The employees are part of HRIS where they can access the portal and contribute positively. Finally, reform the whole HR function of banks to achieve their goals timely (Adekola and Sergi, 2018).

The literature reviews in existence on the HRIS proposes that they contain dissimilar impressions on HR transversely banks but provides a little description for this disparity. Early surveys advocated that HRIS was utilised principally to systematise routine responsibilities that replace manual filing. Bohlander and Snell (2019) concluded that HR had overlooked the HRIS strategic opportunity in the firms that make strategic decision making by HR to be effective for banks to officiate their operations. However, the HRIS is applied strategically that contrasts with banks, with the massive majority of banks, are using the HRIS to replace physical processing of HR and reduce operational costs. Adekola and Sergi (2018) and Buzkan (2016) indicated that firms have started utilising a sophisticated type of HRIS like performance management, development and training, remuneration management, and commercial communication. Scholars assess the use of this HRIS in the effectiveness of the HRM in firms listed on stock exchange operating in the Middle East. They further investigated on the five factors of factor analysis. Research participants professed strategic and technical HRM based on the performance and reward of management as maximum significant factors for the application of the HRIS (Buzkan, 2016).

The most common application of the HRIS in the organizations operating in the Middle East is basically in the personnel records, followed by remuneration records. Well-cultured HRIS applications like strategic and technical HRM systems, performance and remuneration control, and corporate governance are also used in Middle East firms. However, the Middle East and multinational corporations did not show a meaningful difference in the application of the HRIS in the firms (Bohlander and Snell, 2019). Scholars explained that HRIS is not a new idea, but it is improving daily with a dynamic environment. The HRIS has impacted on the performance of HRM in these firms.

The literature gap identified in this paper is on the impacts of HRIS to the manufacturing companies in the Middle East. The paper focuses on impacts of HRIS system to the effectiveness of the HRM in the manufacturing firms. After the firm appraisal, the literature review concluded that the use of HRIS has numerous advantages. Still, the primary is HRIS keeps data about the personnel of the firms that assist in intensifying the pace of a snail for the HRP. The HRIS also aids in organising the core activities of 
the HR department in training and expansion, sequential planning, applicant tracing in recruitment and hiring, and professional planning. While exploring the general involvement of HRIS in HRP, it is concluded that HRIS highlights occupied and unoccupied vacancies in an organization very suitably and correctly. Armstrong (2016) attempted to determine if HRIS has reached these potential benefits. The basic change in the modern use of this technology is that it increases the effectiveness of the management system in the organization (Badenhorst-Weiss, Brevis, and Cant, 2018). Its main function is in human resource planning (HRP), which itself is a pivotal activity in any organization. Unsuitable HRP can lead to additional or fewer numbers of professionals than required. Both overstaffed and understaffed can create undesirable situations. Therefore, in this research, the impacts and application of this HRIS in the manufacturing firms are quantitatively identified based on the effectiveness of HRM in the Middle East.

\section{RESEARCH METHODOLOGY}

The research uses quantitative approach method as it focuses on the impacts of the HRIS system to the manufacturing companies in the Middle East. The section describes the applied methodological approach in the efforts to achieving the set goals (George, 2017). The approach involves the fashion on how the study was done, problems encountered, and solutions in defining the phenomenon in the study. The research methodology necessitates a systematic approach to solve the problem scientifically using the explanation, prediction, or description of the phenomenon (Gerber and Voelkl, 2020). The quantitative approach entails the numerical representation of the observations that present the description and explanation aimed at reflecting on the research observations. The approach is attained based on the social research that uses empirical description and methods of the phenomenon in the research. The description of these empirical methods is aimed at expressing the research phenomenon numerically in an attempt to relate it to the real world. The aspect of the evaluation of this phenomenon empirically will focus on the point of determining the extent for a specific program that fulfils or fails the policy based on the set standard norms of collecting and analysing the numerical data statistically. The description of this phenomenon involves the aspect of the impacts of using the HRIS system in managing human resources to the manufacturing companies in the Middle East. The nature applied is predicative based on the future models on the procedural understanding of simple statistics based on the set and defined research phenomenon.

\section{Study Design and Measures}

The research focuses on the impacts of the HRIS on the effectiveness of HRM based on the manufacturing companies in the Middle East. The study consists of the effectiveness of HRM as a dependent variable and the HRIS system as the independent variable; top management, effective communication, training programs, support to the IT department, and support to the HR department (Kimani, 2017). In this case, the research will try to establish the impacts of the independent variable on the dependent variables. Since the study is analytical, it will use secondary data obtained from a survey on the HR department to collect the data on the apparel of the manufacturing companies using the convenient sampling method (Kale and Kale, 2020). The data was obtained using questionnaires on the measured statements of the HRIS and analysed based on the unilabiate and bivariate data analysis. The blueprint is based on answering the research questions to achieve the objectives based on the impacts of the HRIS on the effectiveness of HRM in the manufacturing firms in the Middle East. The questionnaires were distributed to the sampled based on the aim of the research using social media and online platforms.

The research design adopted is descriptive since the study lacks standard universal agreement based on the experimental design to use primary data for the effectiveness of the phenomenon (Kuada, 2018). The use of this design provides an accurate representation of the variables based on the relevant study questions that are evidenced by the relationship between the HRIS and the effectiveness of the HRM in the manufacturing companies. The descriptive research design is applied to cases where there are limited knowledge and experience of the researcher based on the phenomenon. In this case, the design satisfies the intent of the researcher based on the relationship between the HRIS system and the effectiveness of the HRM in the manufacturing firms (Hinton, McMurray, and Brownlow, 2014). The philosophy used is positivism since it shows the significance of determining the nature of the study - the perception of epistemological of many researchers' beliefs on the model of measured aspects in the research (Kothari, 2014). The use of these measures aimed at identifying the key impacts of the HRIS on the effectiveness of the HRM. 


\section{RESULTS}

The research methodology was done quantitatively to obtain the findings that represent the information numerically in the aspect of representing the prediction of the model-based impacts of the HRIS on the effectiveness of the HRM in the manufacturing companies. The information obtained from the survey was coded numerically to allow for the analysis using the SPSS statistical software (Kumar, 2019). The study was based on the formulated hypotheses aimed at achieving the objectives of this study. The study was based on the null hypothesis (Ho) and the alternative hypothesis (H1). The analysis focuses on defining the relationship between these variables that helps in determining the impacts of the HRIS on the effectiveness of the HRM in manufacturing firms through an inferential test, descriptive statistics, chisquare, and correlation. The following are the hypotheses tested in this study using the statistical methods.

Ho. There are negative impacts of the HRIS on the effectiveness of the HRM department on the manufacturing firms in the Middle East.

H1. There are positive impacts of the HRIS on the effectiveness of the HRM department on the manufacturing firms in the Middle East.

\section{Inferential Statistics}

The quantitative data is tested on validity and reliability to be used in this study to determine the impacts of the HRIS on the effectiveness of HRM on the manufacturing firms in the Middle East. Inferential statistics is an analysis that applies the deduction of the underlying probability distribution to statistical data based on the population and nature of the study (Moores, 2017). Inferential statistics are used to test the reliability and validity of statistical and numerical data in research. The quantitative data is analysed using the reliability scale analysis to obtain the results shown in Table 1 below. The Cronbach's alpha test obtained in this analysis is 0.055 . The value of the alpha test is greater than the standard value of 0.05 , showing that the data obtained was valid and reliable in this study on the impacts of the HRIS system to the manufacturing companies.

Table1. Reliability Test

\begin{tabular}{|l|l|}
\hline Cronbach's Alpha & N of Items \\
\hline .055 & 6 \\
\hline
\end{tabular}

\section{Descriptive Statistics}

The descriptive statistics gives the analysis of the basics of both the measures of central tendency and dispersion. The measures of central tendency give the averaging of the numerical data, while measures of dispersion give the variation (Schäffner, 2020). The data were obtained from 96 respondents using the questionnaires. In this analysis, it is based on the mean, standard deviation, and skewness of the variables, as shown in Table 2 below of the measured values in this research.

Table2. Descriptive Statistics

\begin{tabular}{|l|l|l|l|}
\hline Variable & Mean & Std dev & Skewness \\
\hline HRIS & 3.48 & 0.25 & 4.98 \\
\hline HRM Effectiveness & 2.15 & 1.12 & 5.78 \\
\hline
\end{tabular}

\section{Chi-Square test}

Chi-square is a statistical test that focuses on measuring the comparison to expectations of the observed data (McCormick et al., 2017). It involves the distribution of statistical data obtained in research to fit the sampled data. The independent test of chi-square is based on the question that shows the relationship between the HRIS and the effectiveness of HRM. In the chi-square test, the degree of freedom is much utilised in the determination of the null hypothesis, and it rejects the null hypothesis based on the population, as shown in Table 3 below. 


\begin{tabular}{|l|l|l|l|}
\hline & Value & df & Asymp. Sig. (2-sided) \\
\hline Pearson Chi-Square & $310.321^{\mathrm{a}}$ & 330 & 0.775 \\
Likelihood Ratio & 175.441 & 330 & 1.000 \\
Linear-by-Linear & 0.432 & 1 & 0.511 \\
Association & 96 & & \\
N of Valid Cases & & \\
\hline
\end{tabular}

The value of Pearson's chi-square obtained from the table above is 0.775 and a likelihood ratio of 1.00 with a linear by a linear association of 0.511 for the data obtained in the study. The value of Pearson chi-square is greater than 0.5 ; this rejects the null hypothesis and accepts the alternative hypothesis. From this test, the alternative hypothesis accepted states that there are positive impacts on the HRIS to the effectiveness of HRM in the manufacturing firms in the Middle East.

\section{Correlation test}

The bivariate correlation of Pearson is a statistical analysis that produces a correlation sample of the coefficient is used to determine the measure of direction and strength of the linear relationship between the continuous variables in the study (Scruggs and Mastropieri, 2016). The correlation also shows the relationship between variables in a study. In this research, the correlation determined is between the HRIS and effectiveness of HRM that is aimed to determine the impacts of the HRIS on the effectiveness of HRM based on the manufacturing firms in the Middle East, as shown in Table 4.

Table 4. Correlation test

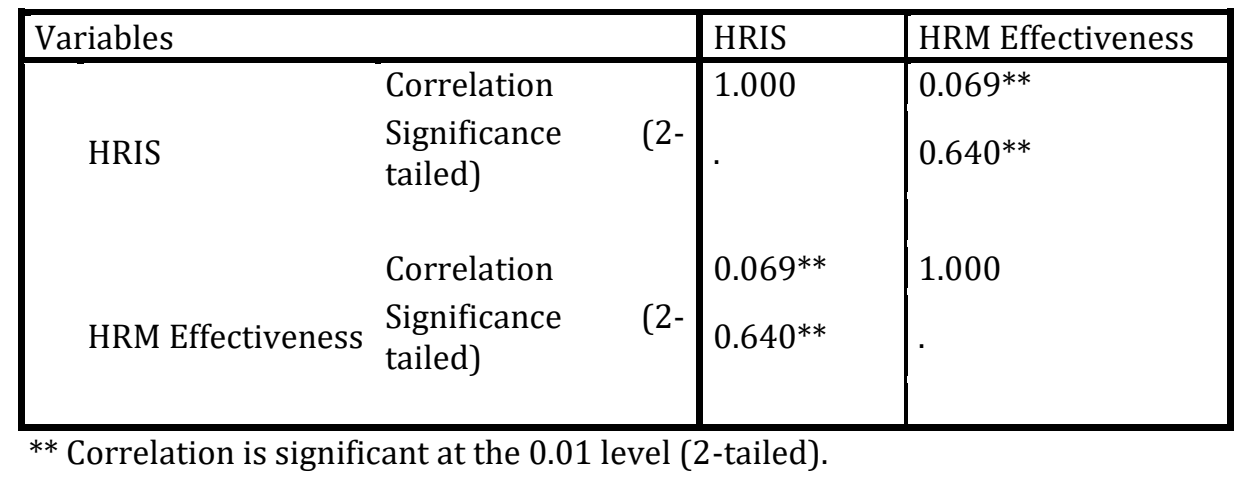

The correlation height and weight for the analysis remain at 1.0, and the correlation coefficient for the pairwise non-missing changed from 0.69 to 0.64 . The correlation weight and height are statistically significant to the linear relationship of the p-value less than 0.1 (Skiadas and Bozeman, 2019). The direction of this relationship between variables is positive, meaning that they correlated positively since they changed at unison with an approximate scale that ranges from 0.64 to 0.69 . From these results, it shows that there is the relationship between HRIS and HRM effectiveness hence showing that there are positive impacts of the HRIS on the effectiveness of HRM to the manufacturing firms in the Middle East.

\section{DISCUSSION}

From the results above, the factors of the HRIS system correlate positively to the effectiveness of HRM in the manufacturing companies. In the chi-square test, the Pearson's chi-square shown is $77.5 \%$ on this correlation in the analysis. In comparison with the significant p-value of $10 \%$ in the correlation coefficient, then the relationship between the HRIS and effectiveness of HRM is obtained by summing the above to obtain an approximation of 85\%. Therefore, results reveal that the HRIS explains approximately $85 \%$ of the selected manufacturing firms in the Middle East variance in the HRM. The results are similar to the major finding of the research conducted by Rainer and Cegielski (2020) based on the relationship between human resource management practices, and firm productivity of National Stock Exchange (NSE) firms was significantly positive. For every one-unit increase in the utilisation of HRM, firm performance rose by $35 \%$. These results suggest that HRM practices that are directed at ornamenting service practices by use of HRIS such as long-term service relations, productivity contingent rewards, motivating and 
conducive work environment, investment in employee training and development programs improve firm performance (Bhattacharyya, 2016).

Previously, much of the prevailing literature, which is based on studies done locally and abroad in the private sector, merely showed a positive linear connection between HRM practices and firm performance (Batallán, 2019). The research highlights some comprehensions in the area of governing the employment relationship, with special emphasis on the Middle East scenario and its background needs as a developing country (Pouransari, 2016). From human capital theory, it can be argued that people possess expertise, knowledge, and aptitudes that provide economic worth to firms. The higher the prospective for employee contribution in an institution, the more probable it is that the corporate will invest in human capital via suitable human resource management practices, and these investments will, in turn, lead to potential individual performance and grander firm productivity. Therefore, a human capital theory maintained that human resource and how it is embraced is a significant drive in human resource management practices and firm performance connection. The results of this study thus concurred with the Resource-Based View Theory by Barney, as agreed by Payne and Petrenko (2019).

These findings denote that NSE listed firms have strategized HRM practices that augment employee results, specifically employee proficiency, hard work, and consent. These findings are in line with the resource-based view according to Barney, which emphasizes the need for firms to warrant that they integrate supportive human resource management practices that contribute in increasing employee expertise, obligation, and empowerment to realise appropriate employee results that distinguish their employees from other firms' competitors for continued superior firm productivity. The irrelevant relationship between employee outcomes and firm performance can be associated with the incompetence of systems of human resource information system policies, performs, protocols, and procedures that help achieve the enactment needs of staff. Such HR activities include internal motivation, HRIS policies, and regulations via which firms fail to offer present workforces the vision of progressing to sophisticated positions.

Another clarification for the inconsequential relationship between human resource practices and firm productivity can be linked to the vibrant changes that the NSE listed firms are thriving in that are frequently changing. Some of the staff may be facing difficulties in change management. Employees in some of the NSE listed firms may also be witnessing shortcomings in tackling difficulties that they may be coming across, which in turn may negatively be impacting their loyalty and empowerment heights, which in turn may lessen firm performance. The current findings of the study that there is a trivial relationship between employee practices and firm performance are not corresponding with the resource-based view theory, which advocated that firms need to improve their central capacity for promising performance. The findings tend to propose that the NSE listed firms might not have established procedures and arrangements that enrich employee production to heighten employee capability, and empowerment (Osei Nyame and Boateng, 2016).

The study was designed to appraise the moderating impact of administrative learning on the relationship between HRIS and employee practices. The first finding was that administrative learning did not have a substantial inspiration on the connection between HRIS and employee practices. Therefore, this means that the utilisation of organizational learning into the regression model produces irrelevant results. The surveyed organization $\mathrm{s}$ might have failed and lagged to institute the required modification with the dynamic demands by implementing and adjusting expertise management methods and disseminating knowledge that assist them in model competencies and human resource practices (Longenecker, 2019).

The inconsistency of the finding with previous studies may also be accredited to the inappropriate organizational practising aspects such as inferred and recognisable knowledge that has not modelled firm detailed skills and expertise. Henceforth, lack of knowledge can trigger decisions, policies, and regulations that can strengthen HRIS practices that can transform employee culture and work values, resulting in promising superior productive activities. Theoretical and empirical literature supports the assertion that an outstanding competitive strategy controls the linear connection between the use of HRIS on employment practices and firm performance (Hanif, 2017). The finding of the current study is regular with existing studies. Employee practices portrayed in their aptitude, expertise, and loyalty have a significant impact on firm performance, particularly when they are brought into line with the firm's competitive strategy on aspects like operational costs and differentiation (Daniel, 2017).

\section{CONCLUSION}

Grounded on the above results, the study concludes that HRIS impacts positively on the HR practices and firm productivity at NSE listed companies to a high level. The application of human resources to the best 
advantage, corporates input in human resource that needs assessment. For the HR investment to pay-off, it should be carefully customised and implemented and aligned to organizational objectives and strategy. The human resource practices approach is consistent, logical and result-oriented and that the human resource practices and productivity function are pivotal for the transformation of behaviour and culture and reinforcing the new organization politics. The findings illustrate strongly that practices that are incorporated in the human resource information systems had a greater impact since personnel can easily access it at their convenient times. This warrants that professionals can achieve skills to prosper themselves at any time. Generally, the outcomes revealed that there is a strong linear connection between the HRIS and the HR practices and corporate performance for listed manufacturing companies in the Middle East. In light of these observations, the research recommends that since there is a strong linear connection between Human Resource Information Systems and human resource practices in companies listed at the Securities Exchange, the management of the institutions should keep up with evolving trends in the HRIS.

\section{REFERENCES}

Adekola, P. A., \& Sergi, P. B. (2018). Global business management: A cross-cultural perspective. Ashgate Publishing. 7(1), 20-70.

Armstrong, M. (2016). A handbook of human resource management practice. Kogan Page Publishers. 3, 58-60.

Badenhorst-Weiss, H., Brevis, T., \& Cant, M. (2018). Business management: A contemporary approach. Juta and Company. 5, 20-32.

Barney, J. B., \& Clark, D. N. (2007). Resource-based theory: Creating and sustaining competitive advantage. Oxford University Press on Demand. 1 (3), 58-70.

Batallán, G. (2019). Anthropology and research methodology. Oxford Research Encyclopedia of Education. 7 (2), 16-40.

Bhattacharyya, D. K. (2016). Research methodology. Excel Books India. 7, 12-14.

Bohlander, G. W., \& Snell, S. (2019). Managing human resources. Cengage Learning. 8, 125-201.

Buzkan, H. (2016). The Role of Human Resource Information System (HRIS) in Organisations: A Review of Literature. Academic Journal of Interdisciplinary Studies. 7 (4), 401-412.

Daniel, K. S. (2017). Studying human resource information systems implementation using adaptive structuration theory: The case of an HRIS implementation at Dow chemical company. Proceedings of the 1st International Workshop on Human Resource Information Systems, 2, 13-28.

Eckert, R. (2016). Business innovation management and business innovation factory. Business Innovation Management, 2 (3), 58-70.

George, G. M. (2017). SPSS statistics versus SPSS modeller: Can I be a data miner using SPSS statistics? SPSSreg Statistics for Data Analysis and Visualization, 275-302. 5 (3), 101-115.

Georgiades, S. (2015). Employee engagement implementation leading to employee creativity. Employee Engagement in Media Management, 7, 83-100.

Gerber, S. B., \& Voelkl, K. E. (2020). The SPSS guide to the new statistical analysis of data: By TW. Anderson and Jeremy D. Finn. Springer Science \& Business Media. 2 (3), 501-534.

Hanif, F. (2017). Impact of human resource information system (HRIS): Substituting or enhancing HR function. SSRN Electronic Journal. 2 (1), 5-9.

Hinton, P. R., McMurray, I., \& Brownlow, C. (2014). SPSS explained. Routledge. 6 (3), 312-354.

Hogler, R. L. (2016). Transforming employment relationships: Implications for human resource management. Human Resource Management Review, 6(1), 75-88.

Kale, A., \& Kale, A. (2020). Basics of research methodology. Essentials of Research Methodology and Dissertation Writing, 2(1), 3-6.

Kavanagh, M. J., Thite, M., \& Johnson, R. D. (2017). Human resource information systems: Basics, applications, and future directions: Basics, applications, and future directions. SAGE. 6, 412-450.

Keenan, P. (2020). Geographic information systems and location analytics for business and management. Oxford Research Encyclopedia of Business and Management. 6, 58-70.

Khrais, L.T. (2020). Role of Artificial Intelligence in Shaping Consumer Demand in E-Commerce. Future Internet, 12(12), $226-240$.

Khrais. L T. (2020). IoT and Blockchain in the Development of Smart Cities. International Journal of Advanced Computer Science and Applications, 11(2), 153-159.

Khrais, L. T., Mahmoud, M. A., \& Abdelwahed, Y. M. (2019). A Readiness Evaluation of Applying eGovernment in the Society: Shall Citizens begin to Use it?. 10(9), 55-59. 
Khrais, L. T. (2018), The Impact Dimensions of Service Quality on the Acceptance Usage of Internet Banking Information Systems. American Journal of Applied Sciences, 15(4), 240- 250.

Kimani, D. F. (2017). Survey says Survey methodology. Communication Research Methodology, 2, 28-39.

Kolatshi, F. H. (2017). Factors affecting the acceptance and impact of human resource information systems (HRIS): Evidence from HR professionals in Libyan companies. 4 (2), 418-458.

Kothari, C. R. (2014). Research methodology: Methods and techniques. New Age International. 4, 254-301.

Kuada, J. (2018). Research methodology: A project guide for University students. Samfundslitteratur. 2 (4), 212-245.

Kumar, R. (2019). Research methodology: A step-by-step guide for beginners. SAGE Publications. 4, 124125.

Lehmann,E. E. (2019). Corporate governance in business and management. Oxford Research Encyclopedia of Business and Management. 3, 28-45.

Longenecker, J. G. (2019). Small business management: Launching and growing new ventures. Cengage Learning. 8 (7), 412-452.

McCormick, K., Salcedo, J., Peck, J., \& Wheeler, A. (2017). SPSS statistics for data analysis and visualisation. John Wiley \& Sons. 2, 325-329.

Moores, D. F. (2017). Research methodology in deaf education. Oxford Scholarship Online 2, 5-6.

Osei Nyame, P. K., \& Boateng, R. (2015). The adoption and use of the human resource information system (HRIS) in Ghana. Proceedings of the 17th International Conference on Enterprise Information Systems. 12, 110-112.

Payne, G. T., \& Petrenko, O. V. (2019). Agency theory in business and management research. Oxford Research Encyclopedia of Business and Management, 5, 27-62.

Pouransari, S. (2016). The effect of human resource information systems (HRIS) on staff retention: A study of recruitment and selection in a UK based hospitality organisation. 6, 24-70.

Rainer, R. K., \& Cegielski, C. G. (2020). Introduction to information systems: Enabling and transforming business. John Wiley \& Sons. 8, 261-270.

Rao. (2017). Human resources management: Text and cases. Excel Books India. 1 (3), 518-570.

Schäffner, C. (2020). The role of discourse analysis for translation and in translator training. Multilingual Matters. 2, 58-70.

Scruggs, T. E., \& Mastropieri, M. A. (2016). Applications of research methodology. Emerald Group Publishing. 4 (2), 125-130.

Skiadas, C. H., \& Bozeman, J. R. (2019). Data analysis and applications 2: Utilisation of results in Europe and other topics. Wiley-ISTE. 7, 58-70.

Soule, S. A. (2018). Social movements and their impact on business and management. Oxford Research Encyclopedia of Business and Management, 2 (1), 6-9.

Sulastri, H. (2018). IT strategy of human resource information system (HRIS) to achieve green its strategy. Jurnal Rekayasa Sistem \& Industri (JRSI), 4(2), 15-18.

Torres-Coronas, T., \& Arias-Oliva, M. (2018). Encyclopedia of Human Resources Information Systems: Challenges in e-HRM: Challenges in e-HRM. IGI Global. 6 (5), 428-458.

Trivena, C., \& Silintowe, Y. B. (2019). Efektivitas Sistem Kearsipan Elektronik human resource information system (HRIS). Jurnal Sekretaris \& Administrasi Bisnis (JSAB), 3(2), 165. 